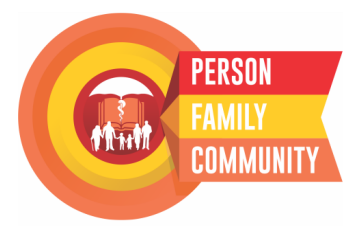

Journal Homepage:

https://jurnal.ugm.ac.id/rpcpe

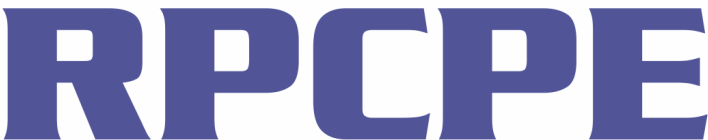

ISSN 2613-943X (print) ISSN 2620-5572 (online)

Review of Primary Care Practice and Education (Kajian Praktik dan Pendidikan Layanan Primer)

\title{
Rural Health Response and Community Preparedness for the Covid-19 Pandemic
}

\author{
Nita Arisanti ${ }^{*}$, Trevino A Pakasi², Syarhan ${ }^{3}$
}

\footnotetext{
${ }^{1}$ Department of Public Health; Faculty of Medicine; Universitas Padjadjaran; Indonesia

${ }^{2}$ Department of Community Medicine; Faculty of Medicine; University of Indonesia; Indonesia

${ }^{3}$ Insepar Clinic; Indonesia
}

Presented at the webinar organized by the collaboration between the Indonesian Family Medicine College, the Indonesian Family Doctors Association, the Indonesian Society of Teachers in Family Medicine, the Review-Journal on Primary Care Practice and Education, and the Center for Policy Management, the Faculty of Medicine, Gadjah Mada University on April 22, 2020.

Corresponding Author:

Nita Arisanti: Department of Public Health, Faculty of Medicine, Universitas Padjadjaran

Email: nita.arisanti@unpad.ac.id

To cite this article:

Arisanti N, Pakasai TA, Syarhan. Rural Health Response and Community Preparedness for the Covid-19 Pandemic. Rev Prim Care Prac and Educ. 2020; 3(3): 8-10.

\section{INTRODUCTION}

Covid-19 is a highly contagious disease and has infected more than seven million people worldwide. Deaths due to this disease have reached 418,000 deaths in June $2020^{1}$. Based on data from the Indonesian Covid-19 Task Force, there were 172,053 cumulative cases with a death rate of $4.3 \%$ in Indonesia up to August 30, 2020.

Indonesia is an archipelago country which has different geographical characteristics. Currently, access to basic healthcare and quality of basic health services has not reached all regions, especially those in underdeveloped, remote and archipelago areas. Health problems in rural areas become a concern for Indonesian government. This is because around $43 \%$ of people live in rural areas or around 116 million people. Government should pay attention to rural health problems as well as urban health. Likewise, during the Covid-19 pandemic rural area will face same problems to Covid-19.

\section{Rural health response to the Covid-19 pandemic}

The problems in rural and urban areas have their own characteristics. These differences occur due to differences in geography, customs or culture, socio-economy, politics and access to health services ${ }^{2}$. Economy and geographical location intersect to form a gestalt triad determining healthrelated disparities in rural areas. Methods: We critically profile each component of the deterministic triad in shaping current healthrelated disparities in rural areas; evaluate the uniquely composed intersections of these disparities in relation to Human Papillomavirus (HPV These factors can be risk factors for the incidence of the Covid-19 pandemic or support efforts to control Covid-19.
During the Covid-19 pandemic, rural communities have the same risk as urban communities. Several studies stated that rural areas have a high risk of Covid-19 transmission ${ }^{3,4}$. Several factors include community characteristics, population mobilization, rural health capacity, government policies and behavior of rural communities as well as the resilience ${ }^{3,5,6}$. Most of rural communities are old age group, low education, low socioeconomic status, have comorbidities and do not have health financing ${ }^{1,3,7}$. A study in USA stated that the high incidence of Covid-19 in rural areas occurs because of the formation of immunity, symptomless diseases and the spreading of virus very easily and quickly. Hospitals in rural areas also experience a high burden in treating Covid-19 patients ${ }^{4}$. However, more attention is paid to the incidence cases in urban areas ${ }^{3}$.

Apart from being a risk factor, several peculiarities of rural communities can support the control of this pandemic.3In terms of customs and culture, rural communities have a high value of community solidarity. These values can be embedded in everyday life $^{2}$. During the Covid-19 pandemic, the culture of mutual cooperation has become stronger to remind people of healthy behavior.

Paying attention to risk factors and other aspects in rural communities, has implications for efforts to prevent the spread of Covid-19 in the community ${ }^{3}$. Prevention efforts in the pandemic era can be carried out by paying attention to the health system in rural areas including access and referrals to higher healthcare, the existence of socially isolated community groups, the impact on community economic problems and the strengths of the community ${ }^{3,7}$. 
In tackling Covid-19, all stakeholders must be involved. Doctors can act as providers, educators, and collaborators The public should understand of its role and gets information regarding the virus which in turn can practice healthy behaviors. The government issues policies that are beneficial to all parties ${ }^{8}$.

\section{Community Readiness to Covid-19 Pandemic}

Is it okay to travel during an outbreak? We often hear this question, especially as we approach religious holidays. In this year's Eid season, President Joko Widodo prohibited going home in the middle of the corona pandemic. There are several reasons that people are not recommended to going home.

In March 2020, researchers from the Eijkman Organization and LIPI made predictions of how much Covid-19 would occur. The model adapted from the pandemic incidence model in Italy and Iran. The Italian model depicts a doubling of cases in five days, while in Iran every 7 days. If we look at these two models, by the end of April there will be around 70 thousand cases in Indonesia compared to around 20 thousand in Iran. This figure will become a reality or not depending on the detection and prevention efforts undertaken by the community, health workers and the government.

During this pandemic, what can doctors do in providing travel advice or going home? As doctors, we must think in terms of community and culture. The goal is to keep individuals or families healthy, including the community by using existing resources in the family. As family doctors which we are close to the community, our job is to manage risks of individuals and families.

The first step is asking the patient for the reason of coming to the doctor. This often goes unnoticed by doctors because doctors think more towards disease. The second is to explore risk factors in patients and their families and the third to explore health problems, including mental problems. When the patient is about to travel during this pandemic, the first thing to be asked is the reason for the trip. Are there important reasons for traveling 9 ? Another problem that must be considered is returning to the place of origin.

So, here we will discuss a new multidisciplinary named travel medicine. The founder is epidemiologists from Switzerland. Travel medicine services comprising of service from the pre-travel assessment, during the trip and after the trip (returning to the area of origin). In the Pre-travel assessment, the doctor must conduct a risk assessment. During the trip, doctors provide education on warning signs and accessible health services. After the assessment, the doctors provide interventions to reduce or decrease risks ${ }^{10.11}$.

A pre-travel assessment is aimed to risk identification. If the travel is not very important, the doctor can conduct counseling to postpone the trip ${ }^{11,12}$. The doctor must know the extent to which the patient understands about Covid-19, his immune abilities and the risks that will be caused when he travels to the destination and return to the place of origin. Doctors have to identify the patient's knowledge, expectations and thoughts so that we can provide specific travel advice as needed. At the time of the spread of Covid-19, the community have to be vigilant because traveling from one area to another would carry the virus even without symptoms.

The next step is to provide recommendations and supplies for traveling. Patients need further education in more detail such as travel time or period, activities at their destination, residence at the destination, home situation and the mode of transportation used. The education provided includes healthy behavior and prevention of transmission as well. If patients are close contact or conformed case of Covid-19, they are prohibited to travel. They tend to spread the virus either on the way or at the destination ${ }^{13}$. Recommendations that can be given are whether to cancel the trip, or postpone the trip, or still leave but with caution. The decision is up to the patient, not the doctor.

What the patient can do at the destination? If the patient comes from the epicenter, he should be assessed and rechecked. The assessment can be done online. Health workers or doctors at the destination can educate how to do new behaviors, social distancing and physical distancing ${ }^{9,13}$. This does not mean that they are completely far away and can not communicate, but we make a distance of 1-2 meters to avoid reach of the droplets. Be diligent in cleaning floors, touchable surfaces, be aware of the direction of the wind so that the droplets do not spread directly and so on. Those advices can be given online. Then, if there are symptoms, the health worker can educate that this is not a dangerous person who must be isolated. Health workers shoud suggest patient to stay at home, in their own room. Pay attention to good ventilation, windows, good lighting, so that people can get sunlight.

Creating a Covid-19 alert society requires a clarity on the roles of the community, health workers and government. Health workers should be reporting cases actively and perform preventive measures according to the standard protocols. Health workers in rural make a good coordination with specialists in cities, make online communication to be able to make online referrals. For this reason, health workers need to be trained to conduct travel risk assessments and implement online health services ${ }^{14}$.

\section{CONCLUSION}

People in rural and urban areas are at the same risk of contracting Covid-19. Doctors in primary care can deliver their roles and duties such as providing education, becoming role models, collaborating with health stakeholders, policy makers, or with other organizations to provide more effective education regarding the prevention of Covid-19. Preparing community readines, doctors can perform risk assessments and provide health education as well as travel advice.

\section{REFERENCE}

1. Paul R, Arif AA, Adeyemi O, Ghosh S, Han D. Progression of Covid-19 From Urban to Rural Areas in the United States: A Spatiotemporal Analysis of Prevalence Rates. J Rural Heal. 2020; 00: 
$1-11$.

2. Thomas TL, Diclemente R, Snell S.Overcoming the triad of rural health disparities: How local culture, lack of economic opportunity, and geographic location instigate health disparities. Health Educ J. 2014; 73 (3): 285-94.

3. Peters DJ. Community Susceptibility and Resiliency to Covid-19 Across the Rural-Urban Continuum in the United States. J Rural Heal. 2020; 36 (3): 446-56.

4. Kaufman BG, Whitaker R, Pink G, Holmes GM. Half of Rural Residents at High Risk of Serious Illness Due to Covid-19, Creating Stress on Rural Hospitals. J Rural Heal. 2020; 00: 1-7.

5. Narayana G, Pradeepkumar B, Ramaiah JD, Jayasree T, Yadav DL Kumar BK. Knowledge, perception, and practices towards Covid-19 pandemic among general public of India: A cross-sectional online survey. Curr Med Res Pract. 2020; 10: 153-9.

6. Lau LL, Hung N, Go DJ, Ferma J, Choi M, Dodd W, et al. Knowledge, attitudes and practices of Covid-19 among income-poor households in the Philippines: A cross-sectional study. J Glob Health. 2020; 10 (1).

7. Henning-Smith C, Tuttle M, Kozhimannil KB. Unequal Distribution of Covid-19 Risk among Rural Residents by Race and Ethnicity. J Rural Heal. 2020; 1-5.

8. Ranscombe P. Rural areas at risk during Covid-19 pandemic. Lancet. 2020; 20: 545 .
9. Kumar A, Nayar KR, Koya F. Covid-19: Challenges and its consequences for rural health care in India. Public Health Pract. 2020; 1: $1-2$.

10. Kozarsky PE, Keystone JS. Introduction to Travel Medicine. In Travel Medicine. 2020. p. 1-3.

11. Brian A, Boraston S, Botten D, Cherniwchan D, Fazal H, Kelton T, et al. Travel medicine. Can Fam Physician. 2014; 60: 1091-103.

12. Hamer DH, MacLeod WB, Chen LH, Hochberg NS, Kogelman L, Karchmer AW, et al. Pretravel Health Preparation of International Travelers: Results From the Boston Area Travel Medicine Network. Mayo Clin Proc Innov Qual Outcomes. 2017; 1 (1): 78-90.

13. Rodríguez-Morales A, Schlagenhauf $\mathrm{P}$, Chaves $\mathrm{T}$, Lloveras $\mathrm{S}$, Angeleri P, Biscayart C. The next big threat to global health? 2019 novel coronavirus (2019-nCoV): What advice can we give to travelers? - Interim recommendations January 2020, from the LatinAmerican society for Travel Medicine (SLAMVI). Travel Med Infect Dis. 2020; 33: 1-4.

14. TA Pakasi. The Need of Trusted Primary Care: Lessons Learnt from the Covid-19 Outbreak in Indonesia. Rev Prim Care Pr Educ. 2020; 3 (2): 3-5. 